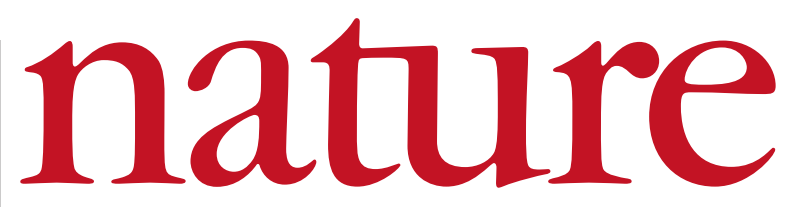

15 April 2004 Volume 428 Issue no 6984

\title{
True lies
}

Attempts to fool the public into mistakenly believing that lie detectors work do not make for either good law enforcement or sound public policy.

I

f you are ever unfortunate enough to take a polygraph lie-detector test, you will be told by its administrator to answer a question falsely. For instance, you might be told to say 'no' when asked if it is Thursday, even though it is. This is to establish a baseline for lying, the examiner will say. Even though you may feel very little guilt about doing just as you are told, the sensors strapped to your body will register changes in pulse, breathing and sweating. Or so you will be informed.

In fact, the polygrapher does not even need to read the traces, because they are unlikely to show anything, according to polygraph training manuals. The purpose of this 'test' is to establish in your mind the infallibility of the machine - if you lie, it will catch you.

As a result, a polygraph exam is only as useful as the examinee thinks it is. A nervous subject is more likely to betray a lie as much through intonation or behavioural changes as through any physiological parameters. Polygraphers are trained to pick up on such cues, making the polygraph a useful tool for interrogation.

But that's not the same as calling it a lie detector. In fact, the instrument's reliability in detecting lies has been thoroughly discredited, most recently after an exhaustive review by the US National Academy of Sciences. In a 2003 report, an academy panel concluded that the tool was worse than useless for catching spies - its main purported national-security function. Spies can learn to defeat the machine, the panel pointed out, and their passing score merely serves to bolster their credibility.

The Department of Energy responded by reducing the number of employees at US nuclear weapons laboratories who are required to take the exam. But other US government agencies have been slow to follow suit, arguing that the polygraph remains useful to them.

New detection technologies are being rolled out in response to current security concerns in the United States (see page 692). These include devices that monitor brainwaves and cameras that read heat signatures in the face. But there are alarming signs that the inventors of these tools are more interested in getting them into the field than in doing the research needed to see if they work.

As with the polygraph, the problem lies with the seductive appeal of technology. In the courtroom, juries are far less likely to question the results of a 'scientific' test than the testimony of a witness. Consequently, the polygraph is now banned as evidence in most states.

If the purpose of these tests is really intimidation, then any technology will do, as long as subjects believe that it works. But if the goal is to discover deceit, then the technology must be validated by solid research. If this is to be done, the US government will have to engage independent scientists - rather than people who work for the companies marketing the machines, or the agencies that plan to deploy them, as is currently the case. Only then will the truth come out.

\section{Why China needs an NIH}

Chinese biomedical scientists are right to push for a research agency that will distribute grants on the basis of peer review.

$\mathrm{T}$ he emerging strength and influence of Chinese biologists, working at home and abroad, is not yet adequately reflected in the structure of research institutions in China itself. Last April, Zhu Chen, vice-president of the Chinese Academy of Sciences, who has been tipped to become China's next science minister, highlighted the issue and proposed the creation of a new research agency akin to the US National Institutes of Health (NIH).

Chen's proposal was quickly backed in a petition by 22 prominent researchers, most but not all of them Chinese, who implored the Chinese government to take it up (see Nature 425, 333; 2003). But the idea is currently bogged down in disagreements over whether it should embrace an intramural component - a set of government laboratories engaged in health research — or confine itself to distributing extramural grants.

In the United States, the NIH has distinguished itself over the decades by combining these two functions. The National Science Foundation, the main US non-biomedical science agency, has, in contrast, successfully confined its activities to the support of extramural work in the universities. There is an argument that the NIH's intramural labs have made a significant scientific impact in their own right, as well as helping its component institutes to stay abreast of their respective areas of interest.

China already has many laboratories, however, including those run by the Chinese Academy of Sciences, that receive support more- or-less directly from the government. Its most pressing need is for a better extramural grant system, to fund research proposals to university scientists on a competitive basis. There is a lot to be said for involving specialists outside China - including the growing cadre of excellent, Chinese-born scientists working in the United States and Europe - in the review component of such a system.

Xiao-Fan Wang, a Chinese-born cancer researcher at Duke University in North Carolina, outlined these ideas at a symposium on 30 March on biomedical alliances between China and California, co-sponsored by Nature and the University of California, San Diego. Chen would have made the presentation himself, but he was denied entry to the United States after he was unable to get a visa.

The current system for funding the life sciences in China is plagued with inefficiencies and shortcomings. Some of these were highlighted by the country's slow response to the emergence of severe acute respiratory syndrome (SARS) in 2002, which encouraged Chen to propose a new biomedical research agency in the first place. The proposal has rapidly gained the support of researchers inside and outside China whose participation in peer review would make it work. If properly implemented, with minimal bureaucracy, full transparency and review of grant proposals by independent scientists, such an agency could greatly accelerate the development of biomedical research in China. 